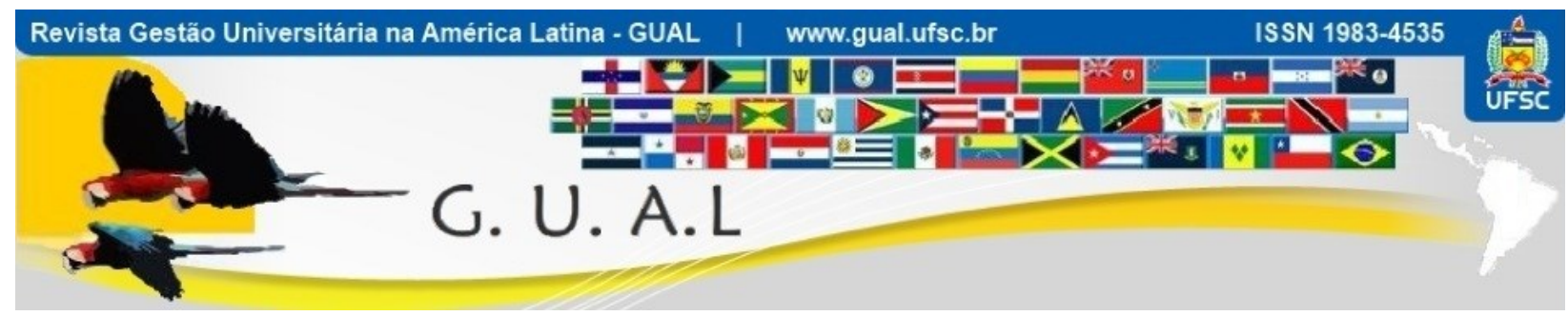

DOI: http://dx.doi.org/10.5007/1983-4535.2013v6n3p332

\title{
EXPERIÊNCIAS VIVIDAS: A TRANSIÇÃO DE LÍDER PARA CONTRIBUIDOR INDIVIDUAL EM UNIVERSIDADES DE SANTA CATARINA
}

\section{EXPERIENCES: THE LEADING TRANSITION TO INDIVIDUAL CONTRIBUTOR IN UNIVERSITIES OF SANTA CATARINA}

Fabiula Meneguete Vides da Silva, Doutora Universidade Federal da Grande Dourados - UFGD fabiulamv@yahoo.com.br

Cristiano José Castro de Almeida Cunha, Doutor Universidade Federal de Santa Catarina - UFSC 01cunha@gmail.com

Recebido em 08/abril/2013

Aprovado em 05/junho/2013

Sistema de Avaliação: Double Blind Review

Esta obra está sob uma Licença Creative Commons Atribuição-Uso. 


\title{
RESUMO
}

Busca-se neste trabalho compreender o processo de transição do líder (reitor ou pró-reitor) para contribuidor individual (professor) em universidades localizadas em Santa Catarina Brasil. A abordagem fenomenológico-hermenêutica de van Manen (1990) foi utilizada a fim de retomar os principais temas desta experiência. Seis ex-gestores universitários emprestaram suas experiências vivenciadas em universidades pertencentes à Associação Catarinense das Fundações Educacionais (ACAFE), através das entrevistas em três tempos preconizadas por Seidman (1998), realizadas entre maio de 2009 e março de 2010. Nas lembranças significativas dos sujeitos da pesquisa, emergiram temas expressivos vividos na transição de gestores para professores. Esses temas foram organizados e serão apresentados nas seguintes categorias: não sou mais responsável pela gestão: um alívio; voltando às origens: é necessário atualizar-se; as relações interpessoais; o tempo; sentindo falta da estrutura; e sofrendo.

Palavras-chave: Transição. Líder. Contribuidor Individual. Fenomenologia. Professor Universitário.

\begin{abstract}
This paper is aimed at trying to understand the transition from leader (rector or provost) to individual contributor (professor) in universities in the state of Santa Catarina - Brazil. The phenomenological hermeneutics approach put forward by van Manen (1990) was adopted in order to revisit important issues in such a transition. Six former university supervisors lent their experiences they had in universities which are part of Santa Catarina Association of Educational Foundations (ACAFE), through three interviews as suggested by Seidman (1998) and which were carried out between May, 2009 and May, 2010. In the participants' important memories, some expressive themes surfaced, which were lived during their transition from supervisors to professors. The themes have been organized into categories, namely: I am no longer responsible for the supervision: a relief; back to the origins: it is necessary to brush up; interpersonal relationships; time; I miss the structure; and suffering.
\end{abstract}

Keywords: Transition. Leader. Individual Contributor. Phenomenology. University Teacher. 


\section{CONSIDERAÇÕES INICIAIS}

As transições são experiências humanas carregadas de emoções, desafios, perdas e oportunidades. Às vezes, elas são ignoradas, ou seu impacto é minimizado pelos gerentes. A realidade é que elas afetam o desempenho das pessoas e o funcionamento das organizações (NININGER, ARDITTI, 2004).

Estudos focados na transição estão relacionados ao processo de aposentadoria de executivos (DE VRIES, 1988), perda de emprego (LATACK, KINICKI e PRUSSIA, 1995; KINICKI, PRUSSIA e MCKEE-RYAN, 2000; ZIKIC e RICHARDSON, 2007), transição de gerente de uma organização para uma atividade autônoma (DUBERLEY, MALLON e COHEN, 2006), ou transição de contribuidor individual para líder (PEARCE II, 1982; KONCZAK, 1994 e THOMAS, 1999; HILL, 2003; HOWARD, 2003).

$\mathrm{Na}$ literatura acadêmica, encontrei muito material sobre o processo de tornar-se gerente, bem como descrições e interpretações acerca dos primeiros meses num cargo de gerência (PEARCE II, 1982; KONCZAK, 1994; THOMAS, 1999; HILL, 2003; HOWARD, 2003). Contudo, inexistem estudos focando o processo de transição de líder para contribuidor individual, apesar da importância significativa dessa experiência na vida desses profissionais.

$\mathrm{Na}$ universidade, é fortemente presente o aspecto da temporariedade do exercício do cargo de gerência. O docente, ao assumir uma coordenação de curso, uma chefia de departamento, pró-reitoria ou reitoria, está ciente de que é por um prazo determinado. Após essa experiência, ele pode retornar à sua função original, o que, na maioria das vezes, significa voltar a ser professor.

Neste trabalho, o "líder" está representado pelo reitor ou pró-reitor universitário, e o "contribuidor individual", pelo professor.

O contribuidor individual é um especialista, um produtor ou um profissional. Sua principal responsabilidade é "realizar tarefas técnicas específicas; sua colaboração para com a organização [...] [é] individual, dependendo acima de tudo de sua competência, experiência e energia" (HILL, 2003, p. 3). São funcionários que executam seu trabalho e não possuem responsabilidade de supervisionar o trabalho de outras pessoas. Por um lado, como contribuidor individual, o professor é responsável apenas por suas atividades, realizando tarefas específicas e programadas, não sendo responsável pelas atividades dos demais colegas. Por outro lado, como líder, o reitor ou o pró-reitor exercem influência sobre as atividades de várias pessoas, possuindo uma agenda imprevisível e dependente de necessidades alheias. 
Buscar compreender o significado da experiência vivida pelo gestor universitário no processo de transição de líder para contribuidor individual faz parte das nossas inquietações, que nos acompanham na caminhada profissional enquanto docentes.

\section{TRANSIÇÃO}

De acordo com Nininger e Arditti (2004), as transições que afetam as pessoas enquadram-se em duas categorias. A primeira delas, foco deste estudo, é o das transições no local de trabalho, estando relacionadas às carreiras profissionais. Essa categoria inclui a entrada no mercado de trabalho, as promoções, as mudanças de funções e, por último, a saída de um emprego remunerado, por opção própria ou por força das circunstâncias. A segunda categoria, a das transições pessoais, inclui transições positivas e também negativas, tais como um casamento (férias planejadas), o nascimento ou adoção de um filho (licença maternidade/paternidade), uma doença debilitante (licença médica por motivo de doença), a perda de um parente (licença por motivo de óbito de um familiar).

Qualquer que seja a transição, ela envolve questões que devem ser tratadas tanto pelas pessoas diretamente afetadas quanto pelas organizações nas quais elas trabalham (SARGENT e SCHLOSSBERG, 1988; NININGER e ARDITTI, 2004). Isso porque as transições são experiências humanas carregadas de emoções, desafios, perdas e oportunidades, dependendo de como são percebidas. Às vezes, elas são ignoradas ou seu impacto é minimizado pelos gerentes. Mas a realidade é que elas afetam o desempenho das pessoas e o funcionamento das organizações (NININGER e ARDITTI, 2004).

Segundo Bridges (1986), a teoria da transição foi proposta com o intuito de analisar o reflexo da mudança nos indivíduos. Nessa perspectiva, mudança e transição são duas dinâmicas paralelas, sendo que a mudança é externa ao indivíduo e a transição, interna ao indivíduo. Dessa forma, a mudança organizacional e a pessoal estão interligadas, o que revela que, sem uma mudança pessoal, através da transição, os esforços da mudança organizacional tendem a fracassar.

\subsection{AS TRANSIÇÕES: DE CONTRIBUIDOR INDIVIDUAL PARA LÍDER E DE LÍDER PARA CONTRIBUIDOR INDIVIDUAL}

Diante da perspectiva de que o professor executa suas atividades cotidianas e não supervisiona as atividades dos colegas, entendemos que o professor pode ser caracterizado como contribuidor individual. Por outro lado, já que o reitor ou o pró-reitor possuem a 
responsabilidade de direcionar as atividades universitárias, podem ser caracterizados como gerentes, gestores, líderes.

As características do trabalho gerencial, no entender de Mintzberg (1973) e Tonelli e Alcadipani (2003), diferem significativamente do que se exige de outros trabalhadores, entendidos neste estudo como contribuidores individuais.

O quadro 1 destaca algumas das transformações requeridas do contribuidor individual para tornar-se gerente.

\begin{tabular}{|c|c|}
\hline DE & PARA \\
\hline Um especialista e executante. & Genérico e definidor da agenda. \\
\hline Realiza diretamente tarefas específicas. & $\begin{array}{c}\text { Orquestra diferentes tarefas, incluindo finanças, } \\
\text { projeto de produtos e fabricação ou organização. }\end{array}$ \\
\hline Fortemente identificado com aquelas tarefas. & $\begin{array}{c}\text { Fortemente identificado com um negócio ou com a } \\
\text { profissão de gerenciamento. }\end{array}$ \\
\hline Um agente individual. & Um elaborador de redes de trabalho. \\
\hline $\begin{array}{c}\text { Consegue fazer as coisas principalmente por } \\
\text { seu próprio esforço. }\end{array}$ & $\begin{array}{c}\text { Consegue fazer as coisas por meio dos outros, } \\
\text { incluindo subordinados sobre os quais exerce uma } \\
\text { autoridade formal. }\end{array}$ \\
\hline $\begin{array}{c}\text { Fortemente identificado como relativamente } \\
\text { independente. }\end{array}$ & $\begin{array}{c}\text { Fortemente identificado como altamente } \\
\text { dependente. }\end{array}$ \\
\hline
\end{tabular}

Quadro 1 Transformação de identidade.

Fonte: Adaptado de Hill (2003).

As transformações requeridas do contribuidor individual para tornar-se gerente são profundas e complexas. Como contribuidor individual, o profissional é responsável, prioritariamente, por suas atividades, realizando tarefas específicas e programadas. Como gerente, ele exerce influência sobre as atividades de outras pessoas, possuindo uma agenda completamente imprevisível e dependente de necessidades alheias.

Os gerentes estudados por Hill (2003, p. 134) vivenciaram muitas situações às quais tiverem que se adaptar, demandando mudanças: “[...] mudança na maneira de se apresentarem, mudança no tratamento com outras pessoas, mudança em relação aos novos conjuntos de pessoas com as quais iriam interagir".

No contexto universitário, essa passagem de professor para gerente também acontece, quando os professores assumem a coordenação do curso, a chefia de departamento, ou até mesmo o cargo de reitor ou pró-reitor. É possível resgatar uma série de textos (HEERDT, 2002; SILVA, 2002; SILVA e MORAES, 2002; MARRA e MELO, 2003, 2005; SILVA, 
MORAES e MARTINS, 2003; ÉSTHER, 2007; KANAN, 2008; SILVA, 2011) que discutem a função gerencial de docentes de universidades brasileiras.

Ésther (2007) pesquisou os reitores, vice-reitores e pró-reitores de oito universidades federais, localizadas no Estado de Minas Gerais, com o objetivo de compreender como os gestores da alta administração de universidades federais constroem sua identidade gerencial. Os resultados demonstram que os professores, ao assumirem os cargos de gerência, em todos os níveis hierárquicos pesquisados, experimentaram a sensação e a prática de que suas atividades são repletas de repetições, papelada, agendas e problemas a serem resolvidos. Tal realidade não difere daquela encontrada nas organizações empresariais, já estudadas por Hill (2003) e Mintzberg (1973).

É possível afirmar que, à semelhança do ambiente empresarial, as transformações requeridas do professor para tornar-se gerente são complexas, já que às atividades de ensino, pesquisa e extensão somam-se as atividades de gestão universitária.

Voltar a ser professor após ter deixado o cargo de reitor ou pró-reitor, ou seja, após ter ocupado uma posição de liderança universitária, requer uma mudança profunda do indivíduo. Nessa transição, o professor deixa de ter responsabilidades de influenciação sobre os trabalhos dos demais integrantes do grupo com o fim de que objetivos sejam atingidos, para possuir responsabilidades, a priori, sobre o seu próprio trabalho.

$\mathrm{Na}$ universidade é fortemente presente o aspecto da temporalidade do exercício do cargo de gerência. O docente assume a reitoria, pró-reitoria, chefia de departamento ou coordenação de curso por prazo limitado. Após essa experiência, pode retornar à sua função original, o que, na maioria das vezes, significa voltar a ser professor.

Por ser uma temática pouco discutida, ainda são desconhecidos e imprevisíveis os comportamentos dos gerentes que voltam a ser contribuidores individuais.

$\mathrm{Na}$ transição de líder para contribuidor individual, podemos destacar algumas transformações requeridas do sujeito, invertendo o quadro 1, adaptado de Hill (2003). Agora, ao voltar a ser contribuidor individual, o sujeito deve, por exemplo, passar de um definidor de agenda para um especialista e executante; deixar de orquestrar diferentes tarefas, para realizar tarefas específicas; deixar de fazer as coisas por meio de outros, para fazer as coisas por seu próprio esforço.

Schlossberg (1981), em seu estudo sobre transição, compreende a transição como um processo de perdas ou ganhos, que depende de como o sujeito se organiza internamente e 
visualiza esse processo. Além disso, o fato de o indivíduo gostar ou não de exercer sua atual função tende a influenciar a forma como vivenciará o processo de transição. Dessa forma, a transição se configura como um processo não linear, dependente das características dos ambientes de pré e de pós-transição e das próprias características do indivíduo.

Sobre as possíveis perdas ou ganhos do processo de transição de líderes para contribuidores individuais, é possível destacar, primeiramente, os seguintes ganhos:

- Relações com a família: percebe-se que, talvez pelo fato de ser complexo o estabelecimento do equilíbrio entre a prática gerencial e as relações de família (SILVA, 2005; SMYRNIOS e outros, 2003), a qualidade da vivência dessa relação é maior para o contribuidor individual do que para o gerente.

- Gestão do tempo: a gestão do tempo, para a prática gerencial, também não se apresenta como uma tarefa simplista, já que a dinâmica do trabalho gerencial é marcada pela imprevisibilidade e inconstância (SILVA, 2005; SKITMORE e AHMAD, 2003), ao passo que o contribuidor individual tem maior controle sobre a gestão de seu tempo, devido ao trabalho mais rotineiro e menos fragmentado.

- Representação da organização: a tendência é que o gerente represente mais a organização em eventos sociais do que o contribuidor individual. $\mathrm{O}$ ex-gerente pode sentir-se aliviado pelo fato de, como contribuidor individual, não possuir essa responsabilidade.

- Responsabilidade pelas atividades do grupo: o ex-gerente passa a focar mais em sua atividade como agente individual e não possui mais a responsabilidade sobre as atividades dos integrantes do grupo, o que pode significar um grande alívio, já que não precisa mais orquestrar todo um grupo de trabalho.

- Hardship: a transição de líder para contribuidor individual também pode se configurar como um hardship. Dependendo de como o executivo se relaciona com essa experiência, esse processo pode se apresentar como uma experiência muito significativa ao aprendizado e, por este prisma, pode se configurar como um momento de ganhos para o profissional (MCCALL JR., LOMBARDO e MORRISON, 1998; MOXLEY e PULLEY, 2004).

- Agenda: o controle sobre o planejamento das atividades do contribuidor individual tende a ser maior se comparado com as atividades do gerente. Enquanto gerente, o indivíduo provavelmente não consegue exercer controle sobre suas prioridades no ambiente de trabalho, já que suas atividades são caracterizadas pela brevidade e fragmentação (MINTZBERG, 1990; KOTTER, 1982; HILL, 2003).

Quanto às possíveis perdas, ressaltamos:

- Perda de poder: o ex-gerente perde espaço, influência, status, o prestígio anexado à posição de gerente. O status social é condicionado à posição social adquirida no ambiente organizacional e na sociedade. 
- Perdas dos desafios: o ex-gerente passa a ter uma rotina com menos desafios, já que o trabalho do contribuidor individual tende a ser mais previsível e com rotinas préestabelecidas (HILL, 2003).

- Representação da organização: o ex-gerente deixa de representar a organização a partir do momento em que perde o status do cargo. Para aqueles que se sentiam orgulhosos de exercer tal ofício, voltar a ser contribuidor individual pode se configurar como uma perda.

- Poder de decisão: o ex-gerente perde o poder principal pelo processo de tomada de decisão; agora não é ele que determinará diretamente o rumo do seu setor ou organização. Enquanto contribuidor individual, o indivíduo pode contribuir no processo de decisão, mas a tendência é que não detenha totalmente o poder decisório.

- Diminuição do salário e benefícios: geralmente o ex-gerente, ao voltar a ser contribuidor individual, perde alguns benefícios concedidos unicamente aos gestores. Isso tende a comprometer a renda familiar, principalmente em se tratando de uma transição não planejada.

A forma como o indivíduo irá reagir ao processo de transição, visualizando mais ou menos aspectos negativos ou positivos, depende também da forma como essa transição acontece: de maneira planejada ou não. A transição de gerente para contribuidor individual tende a ser menos traumática quando o próprio indivíduo a escolhe, ou seja, quando esse processo se dá de maneira planejada, resultante, por exemplo, de alguma insatisfação ou conflitos entre o trabalho e outros papéis da vida. No entanto, a transição não planejada não sofre influência direta do indivíduo que passa por esse processo e pode ocorrer devido a mudanças na política da organização, por exemplo. Nesse último caso, as atitudes e os comportamentos do indivíduo tendem a ser mais negativos, dificultando seu processo de transição.

\section{METODOLOGIA UTILIZADA}

A presente pesquisa está situada no paradigma interpretativo que, segundo Morgan (1980), baseia-se na visão de que o mundo social tem um status ontológico precário, e que a realidade social não existe num senso concreto, mas é o produto das experiências subjetivas e intersubjetivas do indivíduo e interpretativo voltado à visão subjetiva.

Com o objetivo de compreender o significado da experiência vivida pelo gestor universitário no processo de transição de líder para contribuidor individual, por meio de uma abordagem qualitativa, utilizamos a abordagem fenomenológico-hermenêutica (VAN MANEN, 1990). 
Seis ex-gestores universitários emprestaram suas experiências, vivenciadas em universidades pertencentes à Associação Catarinense das Fundações Educacionais (ACAFE), através das entrevistas em três tempos preconizadas por Seidman (1998), realizadas entre maio de 2009 e março de 2010. Essa técnica reúne e explora as falas dos entrevistados, permitindo ao pesquisador compreender profundamente o significado do fenômeno humano.

$\mathrm{Na}$ primeira entrevista, estabelecemos o contexto da experiência do participante, realizando perguntas abertas, com o objetivo de obter o maior número de informações a respeito do sujeito. Por meio desse primeiro contato pessoal, resgatamos os fatos mais marcantes das histórias de vida dos participantes.

$\mathrm{Na}$ segunda entrevista, os entrevistados reconstituíram os detalhes de sua experiência dentro do contexto em que ocorreu. As questões que nortearam essa entrevista foram: "descreva sua experiência vivida como gerente", "descreva a experiência da transição", "descreva a sua experiência vivida como contribuidor individual".

No terceiro encontro, solicitamos aos participantes uma reflexão sobre o significado da experiência vivida. A questão que norteou essa etapa foi: "qual o significado da experiência vivida por você no processo de transição de líder para contribuidor individual?". Além disso, nesta entrevista ratificamos algumas informações obtidas nas entrevistas anteriores.

Um quarto encontro aconteceu com três entrevistados pelo fato de não termos alcançado o objetivo proposto no terceiro encontro. Transcrevendo as entrevistas anteriores, antes de partir para a próxima, percebemos a necessidade de aprofundar com esses três sujeitos alguns temas que não estavam esclarecidos para nós.

Os seis sujeitos significativos deste estudo foram escolhidos de acordo com o método de saturação de dados. O fechamento amostral por saturação teórica é compreendido como a suspensão de inclusão de novos sujeitos quando os dados obtidos apresentam, na avaliação do pesquisador, uma certa redundância ou repetição, não sendo considerado relevante persistir na coleta de dados (GLASER e STRAUSS, 1967).

Após a realização das entrevistas, partimos para sua transcrição, gerando as descrições experienciais.

A transcrição configurou-se como um novo desafio de conhecimento e aprendizado. De posse desses transcritos, debruçamo-nos sobre as entrevistas, lendo e relendo-as para identificar temas analisáveis. Para van Manen (1990), a tematização é uma maneira de controlar e dar ordem tanto para a pesquisa quanto para a escrita. A delimitação de temas na 
pesquisa fenomenológica é uma maneira para encontrar significados do mundo vivido pelo pesquisado, e é realizada tendo como base o estabelecimento de categorias, conforme já destacado anteriormente.

No processo de análise, o tema reflete uma das possíveis direções para o alcance da essência do fenômeno, busca dar forma ao que não tem forma, descreve o conteúdo do fenômeno temporariamente, objetivando alcançar sua essência. O tema é uma redução do fenômeno para chegar à sua essência, representa de forma simplificada o que foi dito, o que foi vivido. O tema desvenda o significado, representando uma forma de ler o que se encontra nas entrelinhas do texto transcrito das entrevistas. Dessa forma, a elaboração de temas é um processo reducionista, e articular temas não exige apenas habilidade ou um processo cognitivo que pode ser descrito e consequentemente aprendido, mas surge de um desejo de encontrar um significado. O significado que se atribui a algo é uma abertura, um processo de revelação, de descoberta, servindo para indicar um aspecto do fenômeno.

O exercício da análise temática permitiu-nos uma aproximação e estruturação da experiência vivida pelos ex-gestores universitários no período em que retornaram para a sala de aula. Tal tarefa implicou leituras e releituras dos documentos escritos, frutos das entrevistas.

\section{OS SUJEITOS E SUAS HISTÓRIAS}

Participaram deste estudo quatro professores e duas professoras, que viveram a experiência da transição de reitores e pró-reitores para professores. Embora nunca tenham deixado de ser professores, viveram um período, em suas carreiras, em que assumiram a responsabilidade pela gestão universitária. Interessa conhecer suas experiências no período em que deixaram de ser responsáveis pela gestão universitária e voltaram a desempenhar a função de professores.

Para resgatar essas experiências, apresentamos, em breves linhas, suas trajetórias de vida, a partir dos aspectos mais relevantes e marcantes de suas caminhadas. Com o objetivo de facilitar a leitura do texto, sintetizamos, no quadro 2, alguns dados importantes de suas histórias.

Os nomes utilizados a seguir são fictícios, a fim de garantir o anonimato dos sujeitos significativos do estudo. 


\begin{tabular}{|c|c|c|c|c|c|c|}
\hline & Miguel & Julia & Lucas & Rafael & Samuel & Beatriz \\
\hline Estado civil & Casado & Casada & Casado & Casado & Casado & Casada \\
\hline $\begin{array}{c}\text { Número de } \\
\text { filhos }\end{array}$ & 1 & 2 & 2 & 2 & 3 & 3 \\
\hline $\begin{array}{c}\text { Área de } \\
\text { formação }\end{array}$ & $\begin{array}{c}\text { Ciências } \\
\text { Exatas e } \\
\text { Tecnoló- } \\
\text { gicas }\end{array}$ & $\begin{array}{c}\text { Ciências } \\
\text { Humanas e } \\
\text { Sociais }\end{array}$ & $\begin{array}{c}\text { Ciências } \\
\text { Biológicas }\end{array}$ & $\begin{array}{c}\text { Ciências } \\
\text { Exatas e } \\
\text { Tecnoló- } \\
\text { gicas }\end{array}$ & $\begin{array}{c}\text { Ciências } \\
\text { Exatas e } \\
\text { Tecnoló- } \\
\text { gicas }\end{array}$ & $\begin{array}{c}\text { Ciências } \\
\text { Humanas e } \\
\text { Sociais }\end{array}$ \\
\hline $\begin{array}{c}\text { Ano da } \\
\text { Graduação }\end{array}$ & 1990 & 1989 & 1975 & 1983 & 1989 & 1971 \\
\hline $\begin{array}{c}\text { Término do } \\
\text { mestrado }\end{array}$ & 2000 & 1993 & 1979 & - & 1992 & 1982 \\
\hline $\begin{array}{c}\text { Término } \\
\text { doutorado }\end{array}$ & - & 2000 & - & - & 1997 & 2007 \\
\hline $\begin{array}{c}\text { Ano em que } \\
\text { entrou na IES } \\
\text { da qual depois } \\
\text { foi reitor ou } \\
\text { pró-reitor }\end{array}$ & 1991 & 1992 & 1976 & 1985 & 1998 & 1986 \\
\hline $\begin{array}{c}\text { Epoca em que } \\
\text { foi reitor ou } \\
\text { pró-reitor }\end{array}$ & $2006-2008$ & $2003-2006$ & $2002-2006$ & $2002-2006$ & $2002-2006$ & $1998-2002$ \\
\hline
\end{tabular}

Quadro 2 Algumas informações sobre os professores que vivenciaram a transição de reitores e pró-reitores para a sala de aula.

Fonte: Silva (2011).

\subsection{SIGNIFICADOS DA EXPERIÊNCIA VIVIDA PELO SER GESTOR UNIVESITÁRIO, NA TRANSIÇÃO PARA A SALA DE AULA}

A transição de carreira pode ser definida como um evento, ou não evento, que resulta em uma reavaliação do que o indivíduo pensa sobre si mesmo e sobre o mundo, provocando, consequentemente, uma correspondente mudança no seu comportamento e nos seus relacionamentos (SCHLOSSBERG, 1981). Isso pode significar que o professor, durante sua carreira docente, deverá passar por vários estágios, cada um deles com exigências específicas, requerendo dele ajustamentos nas esferas da vida ocupacional, financeira, social e psicológica.

$\mathrm{Na}$ carreira universitária, quando passam de reitores e pró-reitores (líderes) para professores (colaboradores individuais), deixam de se envolver na coordenação de seus pares; no tratamento de conflitos com os técnicos administrativos, professores e alunos; na supervisão de atividades diversas; para voltarem a realizar seus trabalhos técnicos como professores, atuando especialmente no contexto da sala de aula, da pesquisa e da extensão. 
A experiência da transição de gestores universitários para a sala de aula foi intensa em significados e envolveu tanto ganhos quanto perdas. O sentimento unânime que caracterizou o retorno para a sala de aula foi o de estar voltando às suas origens, caracterizado por momentos de euforia e de estranhamento pela nova dinâmica estabelecida pelos alunos em sala de aula. A transição para a sala de aula significou, para eles, fazer valer suas escolhas iniciais, retornando para onde tudo começou, só que agora mais maduros e com uma visão da totalidade da universidade. De qualquer forma, essa transição exigiu que fizessem ajustamentos nas esferas de sua vida ocupacional, psicológica e social. Eles tiveram que se adaptar a um novo momento de suas vidas.

Os ajustamentos na esfera da vida ocupacional referem-se ao envolvimento em uma atividade típica de contribuidores individuais. Os ex-gestores passaram a ser professores e precisaram incorporar uma nova rotina de trabalho na sala de aula, diferente das atividades a que estavam acostumados como reitores e pró-reitores. Agora, não precisavam mais despender tempo com a coordenação de atividades, passando a despender seu tempo e esforço em suas atividades individuais, que dependiam somente de seu desempenho e comprometimento.

$\mathrm{Na}$ esfera psicológica, precisaram incorporar em suas vidas o fato de não estarem mais no poder, o que exigiu que aprendessem a respeitar a nova gestão universitária. O processo de realinhamento de suas atividades e responsabilidades também envolveu ajustamentos em nível psicológico.

Os ajustamentos na esfera social relacionam-se ao fato de terem mais tempo para a família e amigos, e de deixarem de se relacionar tão frequentemente com a comunidade acadêmica. Além disso, como professores, não possuíam mais a responsabilidade de representar a universidade, já que perderam o status do cargo de reitor ou de pró-reitor.

No tecer de cada história, nas lembranças significativas dos sujeitos da pesquisa, emergiram temas expressivos vividos na transição de gestores para professores. Esses temas foram organizados e serão apresentados nas seguintes categorias: não sou mais responsável pela gestão: um alívio; voltando às origens: é necessário atualizar-se; as relações interpessoais; o tempo; sentindo falta da estrutura; e sofrendo. 


\subsubsection{Não sou mais responsável pela gestão: um alívio}

Os ex-gestores, ao relembrarem os momentos vividos na transição para a sala de aula, expressaram sentimentos de alívio. Sentiram-se aliviados por não mais terem uma significativa responsabilidade pela instituição. Suas estadas no comando das reitorias e próreitorias foram marcadas por conflitos e embates, o que lhes causou desgastes. Deixar o cargo de gestão significou, para eles, um alívio e um sentimento de dever cumprido, já que entendiam que tinham contribuído para a implementação e concretização de um projeto de universidade no qual acreditavam. Eles julgavam que tinham feito a sua parte. Além disso, sentiam alívio por não mais precisarem se envolver com uma rotina estafante e repleta de fragmentação. Antes, como gerentes, tinham convivido com informações imprecisas, um dia a dia de trabalho fragmentado, sentiam responsabilidades em relação ao futuro da universidade. Depois, como professores, detinham o controle do seu processo de produção e responsabilizavam-se somente por suas atividades.

Agora, adaptando-se às atividades específicas, previamente planejadas, típicas de contribuidores individuais, os professores se sentem aliviados por não mais viverem a fragmentação e a brevidade das tarefas típicas dos gestores. Como contribuidores individuais, eles conseguem gerenciar seu tempo e planejar suas atividades docentes, algo que não lhes foi possível enquanto reitores e pró-reitores.

As diferenças entre as atividades realizadas pelo contribuidor individual e as realizadas pelo gerente foram estudadas por Mintzberg (1973), Hill (2003) e Tonelli e Alcadipani (2003). Esses autores, por meio de suas pesquisas, concluíram que o contribuidor individual pode gerenciar melhor seu tempo e suas atividades, podendo ser um especialista e o responsável pelas suas atividades; já o líder, é responsável não somente pelas suas atividades, mas também pelo desempenho do grupo, sendo um dos responsáveis pelo trabalho dos outros, necessitando orquestrar diferentes tarefas, incluindo finanças, recursos humanos, projeto de produtos, e isso acabada sendo sinônimo de uma rotina estafante, repleta de atividades fragmentadas e não planejadas.

\subsubsection{Voltando às origens: é necessário atualizar-se}

À medida que os ex-gestores voltaram para a sala de aula, sentiram-se retornando às suas origens. Afinal de contas, antes de serem gestores universitários, dedicavam-se à docência. Embora alguns deles não estivessem exercendo a função em sala de aula, todos 
sempre continuaram a se sentir professores, além de gestores. Na verdade, perceberam que estavam numa função temporária, a de líder universitário: "Você estava num período, excepcionalmente, fora. Você voltou às origens, fazer o que você sempre foi [...]" (LUCAS).

O fato de esses ex-gestores se perceberem voltando às origens, no período de transição para a sala, também está relacionado à compreensão de que a gestão se constituiu como uma atividade acadêmica, mas não como a essência do trabalho do professor, pois o que define o trabalho acadêmico do professor universitário é o ensino, a pesquisa e extensão, sendo a gestão considerada uma atividade de cooperação com a instituição.

Os professores perceberam a necessidade de voltar a frequentar mais continuadamente a biblioteca, resgatar seus antigos livros, acessar artigos das suas áreas de formação básica. Durante o período em que foram responsáveis pela gestão universitária, acessavam conhecimentos da área da gestão, deixando de lado suas áreas de formação, nas quais lecionavam antes de assumirem a reitoria e pró-reitoria. Perceberam que, nesse sentido, erraram, muito embora também tenham concluído que não tinham tempo para se envolver com outras questões além das que envolviam a gestão universitária.

A retomada de suas produções acadêmicas e o envolvimento em projetos de pesquisa foram as formas encontradas por esses professores para se atualizarem, para responderem às demandas dos alunos.

A adaptação ao mundo da sala de aula tem sido uma constante, para esses ex-gestores. Eles destacam que as mudanças ocorrem de maneira veloz e que se sentem responsáveis pelo processo de desenvolvimentos de seus alunos. Logo, necessitam viver em um processo constante de adaptação às mudanças.

A aprendizagem do professor deve ser sempre atualizada, devido aos impactos das novas tecnologias na sociedade e na educação. A expressão "manter-se atualizado", no caso daqueles que vivem para produzir e transmitir conhecimento, é mais do que um clichê, é uma exigência fundamental, o que, de fato, os professores puderam sentir na sua volta à sala de aula.

\subsubsection{As relações interpessoais}

As relações interpessoais vivenciadas pelos ex-gestores, após deixarem os cargos, foram importantes no processo de transição para a sala de aula. Os relacionamentos com os colegas de trabalho foram fonte de alegrias e decepções para os professores. Enquanto que o 
apoio familiar e dos amigos foi de essencial importância, proporcionando-lhes acalento e segurança.

Alguns temas essenciais, entrelaçados às questões de relacionamento interpessoal profissional, emergiram das entrevistas realizadas com os ex-gestores: percebendo-se menos importante; sentindo-se perseguido; ainda estão me vendo como gestor; meu olhar ainda é de gestor; e os colegas ajudando na transição.

Enquanto os ex-gestores tentavam se adaptar a uma nova rotina de trabalho, sentiamse menos importantes. Os holofotes, agora, estavam voltados para outra equipe de trabalho, que acabara de assumir a reitoria. Através dos relatos dos ex-gestores, percebemos que, embora tivessem se preparado para atuar em uma nova função e estivessem cientes de que, quando voltassem para a sala de aula, as coisas seriam diferentes e a realidade de trabalho seria outra, eles sentiram, durante a transição, que não eram mais importantes, e aquilo que pensavam já não influenciava mais a gestão universitária. Isso foi vivido com angústia e tristeza:

O sentimento de perseguição configurou-se como um dos temas essenciais, no conjunto de sentimentos experimentados pelos ex-gestores durante o seu processo de transição.

Os professores ressaltaram que se sentiram perseguidos, ao transitarem dos seus cargos de gestão para a sala de aula. O grupo que assumiu a gestão da universidade de alguma forma tentou prejudicá-los, ora não garantindo suas horas-aula em sala de aula, ora dificultando o andamento de alguns projetos aprovados no período em que estavam na gestão, despertando neles, por consequência, sentimentos de indignação e temor.

Mesmo não mais ocupando suas funções na condução da universidade, os ex-gestores percebiam que a comunidade acadêmica continuava a vê-los como gestores. Como professores, já se dedicando às atividades docentes, foram por diversas vezes questionados por alunos, colegas professores, e pela comunidade acadêmica em geral, a respeito do futuro da universidade. As pessoas queriam saber suas opiniões, queriam saber seus posicionamentos. Em diversos momentos, perceberam-se como se ainda estivessem no cargo:

$\mathrm{Na}$ fase de transição, os professores viveram situações conflitantes: no nível superior de gestão, suas opiniões não eram mais relevantes, daí sentiram a "caneta do poder secar"; entretanto, perante os professores, técnicos administrativos e a comunidade externa à universidade, suas vozes continuavam sendo ouvidas. $\mathrm{Na}$ realidade, essa comunidade, 
mediante a confiança dada aos professores durante o período de seus mandatos como reitores e pró-reitores, desejava continuar sabendo suas opiniões sobre os novos rumos que a universidade estava trilhando.

Pensar e, em alguns momentos, agir como gestores, fez parte da história vivida pelos ex-gestores, no processo de transição para a sala de aula. Embora não mais gestores, eles tiveram dificuldade para voltar a pensar somente no seu novo universo de trabalho: a sala de aula e o departamento do qual faziam parte. Eles tinham aprendido a perceber, enquanto gestores, a importância de possuírem uma "visão do conjunto", uma "visão sistêmica", para a realização de uma gestão universitária eficiente.

Já era sabido que a transição de gestores para professores é acompanhada de uma transição de identidade que, por sua vez, não acontece imediatamente após o seu desligamento formal da gestão universitária:

Impregnados pela experiência como gestores, os professores tiveram de se adaptar ao novo contexto de um trabalho que dependeria principalmente deles. Entendendo que o olhar deveria agora estar voltado para a sala de aula, esses ex-gestores perceberam que não era mais necessário envolver-se com as diversas questões complexas oriundas do contexto universitário. Mudar este olhar macro, que visava o futuro da universidade, para um olhar focado apenas na sala de aula, exigiu desses professores readaptações, ajustamentos. O conhecimento múltiplo e a visão do todo, competências necessárias para a atuação enquanto gestores, mostrou-se prejudicial para eles, no período da transição, já que desejavam estar totalmente envolvidos com a nova realidade de trabalho: a sala de aula.

A fase da transição vivenciada por esses professores se traduz como a adaptação a uma nova rotina de trabalho, uma aproximação de novos colegas, um processo de aprendizagem. Os colegas de trabalho ajudaram os ex-gestores a viverem um processo de adaptação mais tranquilo, estando presentes e auxiliando-os a ultrapassarem os obstáculos próprios dessa fase.

A família teve um significado especial para os ex-gestores, como um ponto de apoio, um esteio para eles. Na família, eles encontraram força para viver o processo de transição. Os professores perceberam que os familiares os apoiaram, sobretudo, pelo fato de estarem se desvinculando da principal atividade responsável pelos conflitos, enquanto estavam nos cargos de reitor e pró-reitor. Durante a gestão, sentiram a pressão de seus parceiros e da família, que se sentiam infelizes com a maneira como os líderes estavam vivendo suas vidas. O trabalho na gestão universitária absorveu muito tempo e energia deles, sobrando pouco 
tempo para a vida em família. No entanto, durante a transição para a sala de aula, eles perceberam a família satisfeita, e ao seu lado, apoiando-os no que fosse necessário.

$\mathrm{Na}$ transição, esses ex-gestores perceberam que o seu trabalho como docentes e a sua vida pessoal ficavam em harmonia. Por outro lado, no cargo de líderes, eles não conseguiram administrar o tempo para a família e para o trabalho, já que se dedicaram demasiadamente à carreira e esqueceram de valorizar as outras dimensões da vida. Esse fato é corroborado pelos estudos de Silva (2005).

A família, para esses ex-gestores, representou efetivamente um alicerce e possibilitou que se sentissem fortes para enfrentarem os desafios e as dificuldades típicas das transições.

A qualidade da transição depende dos fatores de adaptação à transição de carreira, como o apoio e as contribuições da família (SCHLOSSBERG, 1981). Os laços familiares servem como defesa, como apoio, e uma barreira contra os terrores vivenciados ao longo da vida (LAING, 1971). As manifestações dos professores revelam que há positivas lembranças da contribuição da família no período em que voltaram para a sala de aula, apoiando-os e encorajando-os a viver uma nova fase de suas vidas, uma fase de intensa adaptação e aprendizagem.

Através dos relatos cedidos pelos ex-gestores, ficou evidente que as dimensões trabalho e família são relevantes em suas vidas e devem ser percebidas de maneira indissociável.

\subsubsection{O tempo}

A sensação de ter mais tempo, ao voltar para a sala de aula, foi rapidamente percebida pelos ex-gestores com euforia. Euforia, porque identificaram rapidamente que não estavam mais envolvidos com a gestão. As atividades da gestão eram altamente fragmentadas e não planejadas, e as atividades realizadas em sala de aula eram planejadas e tinham dia e hora para acontecer. Os professores perceberam que tinham tempo livre, o que foi sentido por alguns de forma bastante intensa, configurando-se, inclusive, como um elemento de transição para uma nova função. "A ruptura maior foi a questão do tempo, porque antes, eu não tinha tempo para nada. Ao perceber o tempo livre, percebi que não era mais reitor, esse foi meu elemento de transição importante" (RAFAEL). 
Alguns dos ex-gestores universitários, a fim de preencher seu tempo livre, resgataram o doutorado, iniciado antes e interrompido pelas atividades da gestão, como é o caso de Miguel. Outros começaram seu processo de doutoramento, como foi o caso de Beatriz.

Outros professores resgataram seus envolvimentos com os projetos de mestrado que estavam sendo conduzidos nas instituições, o que os ajudou a preencherem o tempo livre de que dispunham logo após sua saída do cargo de gestão:

\subsubsection{Sentindo falta da estrutura}

Enquanto gestores, os pesquisados tinham à sua disposição toda a estrutura universitária, composta por equipamentos, espaço físico e pessoas qualificadas, que os apoiavam. Cada um dos ex-reitores e ex-pró-reitores entrevistados possuía um espaço específico para a realização de suas atividades, além de uma equipe que os apoiavam no atendimento das metas traçadas. Foi comum terem à sua disposição uma secretária, que cuidava das suas agendas, assessorando-os no que fosse necessário.

Voltando para a sala de aula, tiveram que aprender a fazer coisas que estavam acostumados a solicitar que outras pessoas o fizessem. A adaptação e o aprendizado exigiram dos professores um grande investimento de tempo, para que pudessem reaver parte do suporte que recebiam por meio do trabalho de outras pessoas. Ao voltarem para a sala de aula, não possuíam mais um espaço privativo e tiveram também que aprender a dividir seus espaços com outros professores e alunos.

Percebemos que, no início da transição, os ex-gestores sentiram fortemente não disporem mais da estrutura que tinham à sua disposição. Mas, com o passar do tempo, aproveitaram esse momento como uma oportunidade de aprendizagem e de exercitarem a flexibilidade necessária para lidar com situações adversas.

\subsubsection{Sofrendo}

Embora os ex-gestores sentissem que estavam voltando às suas origens, voltando a realizar as atividades pertinentes às suas primeiras escolhas na universidade, no período da transição para a sala de aula, o sofrimento foi um sentimento que fez parte deste processo de transição. O sofrimento estava relacionado aos diversos desafios, ao momento em que tiveram que se ajustar a uma nova realidade de trabalho. 
Os professores deste estudo, ao retornarem para a sala de aula, incorporaram um compromisso com uma nova identidade pessoal, orientada não mais para gerenciar pessoas. Como professores, passaram a ser responsáveis pelos seus desempenhos individuais, abraçando uma rotina de trabalho diferente. Percebemos que não estavam preparados, não tinham noção do que seria deixar de ser reitor ou pró-reitor e voltar para a sala de aula, o que lhes causou tanto sofrimento, no início da transição.

O sofrimento vivido pelos ex-gestores estava relacionado aos seguintes fatores: a nova dinâmica na sala de aula; a perda de poder no processo decisório; a percepção de oportunistas; a perseguição sofrida; e a falta da estrutura universitária à sua disposição.

A transição significou, para esses ex-gestores, um momento difícil, um hardship (MCCALL JR., LOMBARDO e MORRISON, 1998; MOXLEY e PULLEY, 2004), no qual tiveram que enfrentar dificuldades, desafios. Para enfrentar tal período, contaram com o apoio de amigos e familiares, que os ajudaram a ultrapassar os obstáculos descritos, além de sua vontade de continuar contribuindo, de continuar a atuar na universidade.

\section{CONSIDERAÇÕES FINAIS}

Após a análise fenomenológica das descrições do período em que transitaram para a sala de aula, observamos, de forma indutiva, que a experiência vivida por esses professores foi relevante na sua transformação em novos docentes, os quais estavam desatualizados quanto aos conteúdos de sua disciplina, mas conheciam muito a universidade, todos os seus processos e mecanismos, o que lhes proporcionava uma visão sistêmica da instituição.

Nas lembranças significativas rememoradas pelos sujeitos desta pesquisa, emergiram temas expressivos vividos na transição de gestores para professores. Tais temas apresentaramse da seguinte forma: não sou mais responsável pela gestão: um alívio; voltando às origens: é necessário atualizar-se; as relações interpessoais; o tempo; sentindo falta da estrutura; e sofrendo.

Chegando ao final da nossa pesquisa, queremos compartilhar algumas lições aprendidas.

Compreendemos que a universidade tem um papel importante no processo de desenvolvimento humano, porque ela prepara, primordialmente, a geração de hoje para cuidar de gerações futuras. Pois sua maior meta é formar pessoas que possam, com seu trabalho, contribuir para o desenvolvimento da sociedade. 
No entanto, essa mesma universidade que auxilia o processo de aprendizagem de pessoas, os seus alunos, às vezes se apresenta negligente no processo de acompanhamento de seus funcionários, como resgatado pelos professores que fizeram parte do nosso estudo.

Percebemos, por meio das constatações apresentadas pelos sujeitos significativos deste estudo, que há carência de apoio e assistência na recondução dos ex-gestores e da sua exequipe de trabalho às atividades de contribuidores individuais. Apesar de a transitoriedade ser algo corriqueiro no ambiente universitário, essas questões não estão sendo levadas em consideração pela gestão dessas instituições de ensino superior. A falta de uma política de realocação de pessoas é algo vivido com muito sofrimento por aqueles que percorrem esse processo da transição.

Dessa maneira, uma das lições aprendidas é que há necessidade premente de se criar um fórum, no contexto universitário, para a discussão sobre as transições vividas pelos professores, e seus reflexos sobre suas vidas, a vida dos seus familiares e da própria comunidade acadêmica.

A compreensão da transição como um processo que envolve ganhos e perdas poderá ser ampliada ou aprofundada por meio de outros estudos que enfoquem tal temática e, sobretudo, através do acompanhamento desse processo por parte do departamento de recursos humanos destas universidades.

Uma instituição universitária deve ter objetivos abrangentes, em relação à satisfação ou adaptação dos seus docentes, no sentido de incluir, em seu planejamento, a preparação e o acompanhamento dos professores em vias de transição, oferecendo-lhes oportunidades de formação que facilitem a continuidade de seu crescimento e sua satisfação pessoal. Diante dessa realidade, faz-se necessário buscar modelos inovadores de gestão de pessoas, para enfrentar as constantes transições requeridas dos professores universitários.

No entanto, as universidades em que os sujeitos significativos desta pesquisa se tornaram reitores ou pró-reitores não possuem um programa para acompanhamento do processo de transição. Todos os entrevistados externaram a necessidade de haver um programa formal nesse sentido. As sugestões sobre quais deveriam ser os conteúdos de um programa de treinamento se concentraram na conscientização dos gestores, e de suas famílias, sobre as possíveis facilidades e dificuldades desse processo e sobre as possíveis perdas e ganhos em sua transição para a sala de aula. 
Esta é outra lição aprendida, a de que há a necessidade de preparar e acompanhar esses profissionais em suas transições, já que esse processo é permeado por mudanças pessoais, perdas e sofrimento.

As universidades nas quais os sujeitos significativos deste estudo viveram suas transições não os apoiaram e não os auxiliaram nesse processo, o que me leva a crer que possivelmente tal realidade esteja sendo vivenciada também em outras instituições de ensino superior.

Essas universidades ainda se ressentem de uma administração adequada às suas peculiaridades. Elas geralmente tendem a adotar os mesmos modelos empregados nas organizações públicas e privadas, sem levar em consideração as especificidades próprias de uma instituição complexa e com objetivos múltiplos e especializados, voltados para a criação e difusão do conhecimento (GRILLO, 1991).

Os dirigentes, entre eles, os servidores técnicos, docentes e outros administradores, representam a base de sustentação da instituição. Por isso as universidades precisam desenvolver políticas e princípios que orientem seus servidores e lhes garantam o seu contínuo desenvolvimento profissional e pessoal, para que estejam motivados e preparados para o desempenho das atividades diversas, contribuindo para a melhoria da qualidade final na instituição. Pois é indispensável contar com pessoal preparado e capacitado para atender às peculiaridades da instituição.

As universidades devem se preparar para novos desafios, principalmente dando maior atenção à gestão das pessoas, no sentido de propiciar condições adequadas para que elas realizem suas funções de maneira harmoniosa, eficiente e eficaz, num clima de desenvolvimento coletivo e mútuo.

\section{REFERÊNCIAS}

BRIDGES, W. Managing organizational transitions. Organizational Dynamics, Summer, 1986, p. 24-33.

DE VRIES, M. F. R. K. The dark side of CEO succession. Harvard Business Review. Boston: v. 66, n. 1, jan./feb.,1988.

DUBERLEY, J.; MALLON, M.; COHEN, L. Exploring career transitions: accounting for structure and agency. Personnel Review, v. 35, n. 3, p. 281-296, 2006.

ÉSTHER, A. B. A construção da identidade gerencial dos gestores da alta administração das universidades federais em Minas Gerais. 2007. 276 f. Tese (Doutorado em Administração) - 


\section{EXPERIÊNCIAS VIVIDAS: A TRANSIÇÃO DE LÍDER PARA CONTRIBUIDOR INDIVIDUAL EM

Faculdade de Ciências Econômicas, Universidade Federal de Minas Gerais, Belo Horizonte, 2007.

GLASER, B. G.; STRAUSS, A. L. The discovery of grounded theory: strategies for qualitative research. New York: Aldine de Gruyter, 1967.

GRILLO, A. N. Desenvolvimento de pessoal nas universidades: em busca da qualidade do ensino superior. Florianópolis: Insular, 1991.

HEERDT, A. P. S. Competências essenciais dos coordenadores de curso em uma instituição de ensino superior. 2002. 100 f. Dissertação (Mestrado em Engenharia de Produção) Programa de Pós-Graduação em Engenharia de Produção, Universidade Federal de Santa Catarina, Florianópolis, 2002.

HILL, L. A. Become a manager: how new managers master the challenges of leadership. 2. ed. Harvard Business School Press, 2003.

HOWARD, C. A. From engineer to engineering manager: a qualitative study of experiences, challenges, and individual transitions for engineering managers in aerospace companies. A Thesis in Workforce Education and Development. Degree of Doctor of Philosophy.The Pennsylvania State University - The Graduate School - Department of Adult Education, Instructional Systems, and Workforce Education and Development. August 2003.

KANAN, L. A. Características do processo de vinculação de coordenadores de curso com o trabalho e com a universidade. 2008. $258 \mathrm{f}$. Tese (Doutorado em Psicologia) - Programa de Pós-Graduação em Psicologia, Universidade Federal de Santa Catarina, Florianópolis, 2008.

KINICKI, A. J.; PRUSSIA, G. E.; MCKEE-RYAN, F. M. A panel study of copping with involuntary job less. Academy of Management Journal, v. 43, n. 1, p. 90-100, feb., 2000.

KONCZAK, L. J. The first-time manager. Personnel Psychology, Summer, v. 47, n.2, 1994.

KOTTER, P. J. What effective general managers really do? Harvard Business Review, v. 60, n. 6, p. 156-167, 1982.

LAING, R. D. A política da família. São Paulo: Martins Fontes, 1971.

LATACK, J. C.; KINICKI, A. J; PRUSSIA, G. E. An integrative process model of coping with job loss. The Academy of Management Review, v. 20, n. 2, apr. 1995.

MARRA, A. V; MELO, M. C. O. L. Docente-gerente: o cotidiano dos chefes de departamento e coordenadores de curso em uma Universidade Federal. In: ENCONTRO NACIONAL DOS PROGRAMAS DE PÓS-GRADUAÇÃO EM ADMINISTRAÇÃO, 27. 2003, Atibaia. Anais... Atibaia: ENANPAD, 2003. 1 CD-ROM.

A prática social de gerentes universitários em uma instituição pública. Revista de Administração Contemporânea, v. 9, n. 3, p. 9-31, jul./set. 2005. 
MCCALL JR., M. W.; LOMBARDO, M. M.; MORRISON, A. M. The lessons of experience: how successful executives develop on the job. New York: The Free Press, 1988.

MINTZBERG, H. The nature of managerial work. New York: HarperCollins Publishers, 1973. 19905

The manager's job: folklore and fact. Harvard Business Review, v. 68, n. 2, mar./apr.

MORGAN, G. Paradigms, metaphors and puzzle solving in organization theory. Administrative Science Quartely, v. 25, p. 605-622, 1980.

MOXLEY, R. S.; PULLEY, M. L. Hardships. In: MCCAULEY, C. D., VAN VELSON, E. (org.). Handbook of leadership development. 2. nd. San Francisco: Jossey-Bass, 2004.

NININGER, J. R.; ARDITTI, M. J. A renovação das organizações: gerenciando transições na força de trabalho. Cadernos ENAP, 28. 92 p. Brasília: ENAP, 2004.

PEARCE II, J. A. Problems facing first-time managers. Human Resource Management, 21, 1, Spring 1982.

SARGENT, A. G; SCHLOSSBERG, N. K. Managing adult transitions. Training \& Development Journal. v. 42, n. 12, dec., 1988.

SCHLOSSBERG, N. K. A model for analysing adaption to transition. The Counseling Psychologist, v. 9, n. 2, p. 2-18, 1981.

SEIDMAN, Irving. Interviewing as qualitative research. New York: Teaches College Press, 1998.

SILVA, M. G. R. Competências gerenciais dos coordenadores do curso de graduação em administração de empresas: um estudo de caso na UCS. In: ENCONTRO NACIONAL DOS PROGRAMAS DE PÓS-GRADUAÇÃO EM ADMINISTRAÇÃO, 26, 2002, Salvador. Anais... Salvador: ENANPAD, 2002. 1 CD-ROM.

SILVA, M. A. da; MORAES, L. V. S. Como os professores aprendem a dirigir unidades universitárias: o caso da UFSC. In: ENCONTRO NACIONAL DOS PROGRAMAS DE PÓS-GRADUAÇÃO EM ADMINISTRAÇÃO, 26, 2002, Salvador. Anais... Salvador: ENANPAD, 2002. 1 CD-ROM.

SILVA, M. A.; MORAES, L. V. S.; MARTINS, E. S. A aprendizagem gerencial dos professores que se tornam dirigentes universitários: o caso da UDESC. In: ENCONTRO NACIONAL DOS PROGRAMAS DE PÓS-GRADUAÇÃO EM ADMINISTRAÇÃO, 27. 2003, Atibaia. Anais... Atibaia: ENANPAD, 2003. 1 CD-ROM.

SILVA, A. B. da. A vivência de conflitos entre a prática gerencial e as relações em família. 2005. 226 f. Tese (Doutorado em Engenharia de Produção) - Centro Tecnológico, Universidade Federal de Santa Catarina, Florianópolis, 2005. 
SILVA, F. M. V. da. A transição de líder para contribuidor individual: a experiência vivida pelo ser gestor universitário. 2011. 273 f. Tese (Doutorado em Engenharia de Produção) Centro Tecnológico, Universidade Federal de Santa Catarina, Florianópolis, 2011.

SKITMORE, M; AHMAD, S. Work-family conflict: a survey of singapourean workers. Singapoore Management Review, v. 25, n. 1, p. 35-52, 2003.

SMYRNIOS, K. X.; e outros. Work family conflict: a study of american and australian family businesses. Family Business Review, v. 16, n. 1, p. 35-51, mar. 2003.

THOMAS, J. Handbook for first-time managers: managing effectively. Women in Business, v. 51, n.1, jan./feb., 1999.

TONELLI, M. J.; ALCADIPANI, R. O trabalho dos gerentes. A mudança que não ocorreu. In: ENCONTRO NACIONAL DOS PROGRAMAS DE PÓS-GRADUAÇÃO EM ADMINISTRAÇÃO, 27., 2003, Atibaia. Anais... Atibaia: ENANPAD, 2003. 1 CD-ROM.

VAN MANEN, M. Researching lived experienced. London, Ontário: The Althouse Press, State University of New York Press, 1990.

ZIKIC, J.; RICHARDSON, J. Unlocking the careers of business professionals following job loss: sensemaking and career exploration of older works. Canadian Journal of Administrative Sciences, 24, 1, mar. 2007. 